\section{Leukaemia linked to radiation}

\section{London}

THE UK government's radiation watchdog, the National Radiological Protection Board (NRPB), has produced the first convincing evidence linking low-level exposure to radiation at work with an increased incidence of fatal leukaemia. The study, published in the British Medical Journal (304, 220; 25 January 1992), suggests that the risk of contracting leukaemia following exposure to low levels of radiation over many years is about twice that calculated from previous studies. Nevertheless, the total number of excess deaths is thought to be relatively low.

The results have led to calls for the tightening of British and international guidelines on the maximum annual radiation dose for nuclear workers. The International Commission on Radiological Protection (ICRP)'s recommendation that workers should receive no more than 20 milliSieverts ( $\mathrm{mSv}$ ) a year, averaged over a five-year period (see Nature 348, 274; 1990 ), is based on studies of the Japanese atom bomb survivors - who received radiation in a single, intense exposure. But NRPB director Roger Clarke, presenting the new results at a press conference last week, said that the uncertainty surrounding the NRPB's new risk estimate is too great to sanction immediate changes to the British or international guidelines.

Although the link between leukaemia and occupational exposure to radiation has been explored before, with inconclusive results, the new NRPB study is unique in its sheer scale. In 1976, the board set up the National Registry of Radiation Workers (see Nature 255, 517; 1975), which documents the radiation doses received by some 95,000 past and present workers in the British nuclear industry. The new NRPB study links these dose data with cause of death, for 6,660 workers who had died by the end of 1988 .

NRPB epidemiologists found a significant positive correlation between radiation dose and death from leukaemia (excluding chronic lymphatic leukaemia, which is not thought to be inducible by radiation). They also found a similar but not statistically significant - trend for fatal solid tumours. Barbara MacGibbon, NRPB's medical director, last week said that it will take several years to determine whether this trend is real: the longer lag time between exposure to radiation and the development of solid cancers means that the number of workers who have so far died is too small a sample for a conclusive analysis.

The radiation-leukaemia link will strengthen the cases of tens of leukaemia patients now trying to obtain compensation from their employers in the nuclear industry. But Clarke last week said that the
NRPB's results should be put in perspective. Despite the association between radiation dose and leukaemia within the nuclear industry, nuclear workers are less likely to die from the disease than the general British population. This is due to the industry's tendency to employ people in good health, a 'healthy worker effect' that was repeated for most of the causes of death examined by the NRPB group. MacGibbon estimated that the number of excess deaths from leukaemia caused by exposure to radiation in the British nuclear industry since the late 1940 s is less than ten (from a total of 47 workers in the NRPB's national registry who died of leukaemia).

Nevertheless, Patrick Green, radiation campaigner with the UK environmentalist group Friends of the Earth, last week called

\section{DRUG DEVELOPMENT}

\section{Washington}

Although most orphan drugs have annual sales of less than $\$ 3-5$ million, some members of Congress are concerned that a handful of companies are exploiting the exclusive marketing provisions provided by the Orphan Drug Act and charging patients exorbitant prices. As a result, companies such as Amgen, Inc., Genentech, Inc., Genzyme Corporation, Eli Lilly and Company and Fujisawa, Inc. are making windfall profits from cumulative sales in the United States that top $\$ 200$ million. Bills have been introduced in both the House and Senate that, while retaining the key incentives of the act, would open up the market to competition for commercially-viable orphan drugs.

Primarily through the guarantee of a government-granted monopoly for a seven-year period, the Orphan Drug Act sets out to foster the development of drugs for diseases that affect fewer than 200,000 people and are likely to be of limited commercial interest. In the nine years since its enactment, the US Food and Drug Administration (FDA) has approved 60 orphan drugs for marketing. By contrast, only ten drugs were developed for the treatment of rare diseases in the 10 years before its enactment.

Although Congress is focusing its attention on four orphan drugs that are racking up block-buster sales (human growth hormone, Epogen, aerosol pentamidine, and Ceredase), at least another eight orphan drugs already on the market or nearing approval have the potential to become block-buster products.

Under the proposed amendments to the act, the orphan status of a drug would for the NRPB's recommended upper limit for radiation exposure at work to be cut from $15 \mathrm{mSv}$ to $10 \mathrm{mSv}$ a year. He is also worried about a forthcoming European Communities' (EC) directive, which is expected to adopt the ICRP's $20 \mathrm{mSv}$-ayear average as a legally binding limit for the $12 \mathrm{EC}$ states. But Clarke, who is an expert adviser to Euratom, the EC agency responsible for the directive, rejected this idea. Until more workers in the national registry die of leukaemia, allowing NRPB to calculate with greater confidence the risk of developing fatal leukaemia after radiation exposure, Clarke argued that it would be inappropriate to reject the current ICRP guidelines. He agreed that the NRPB leukaemia risk estimate, if confirmed, would increase the pressure for a $10 \mathrm{mSv}$-a-year limit, but he thought it more likely that the risk would be "confirmed at the levels we're working with at the moment".

Peter Aldhous

\title{
Orphan drug windfalls?
}

be revoked and competitors allowed to enter the market when cumulative net sales of the drug exceeded a $\$ 200$-million cap. Similar legislation introduced in the House sets the cap at $\$ 150$ million.

Legislative uncertainty that has surrounded the Orphan Drug Act over the past 3 or 4 years is already having an effect on the number of new orphan drugs being developed. An FDA official says there has been a 10 per cent drop in the number of orphan drug applications in 1991 compared to the previous year.

At a hearing last week before a congressional subcommittee, chaired by Senator Howard Metzenbaum (Democrat, Ohio), Genzyme and Genentech were asked to justify the high prices they are charging for their orphan drugs. Amgen, Eli Lilly and Fujisawa, though invited to testify, declined to do so.

Ceredase, manufactured by Genzyme for the treatment of Gaucher's disease, costs patients an average of $\$ 250,000$ in the first year of treatment. Since its approval by the FDA last April, total sales for Ceredase are estimated to be $\$ 120$ million. Although Genzyme executives refused to disclose to the subcommittee details of research and development costs for the drug, Henri Termeer, chairman and chief executive officer of Genzyme, admitted that Metzenbaum's \$50-million estimate was "approximately right". Termeer blames high manufacturing and other incidental costs for the high price.

Even if a version of the bill is passed by Congress, it will still face the daunting hurdle of winning sufficient votes to overcome a threatened presidential veto.

Diane Gershon 